\title{
Interferon alfa-2b Regimen
}

National Cancer Institute

\section{Source}

National Cancer Institute. Interferon alfa-2b Regimen. NCI Thesaurus. Code C160055.

A chemotherapy regimen consisting of interferon (IFN) alfa- $2 b$ that may be used in the treatment of bone cancer; AIDS-related Kaposi sarcoma; desmoid tumors (aggressive fibromatoses); neuroendocrine tumors (NET) of the gastrointestinal (GI) tract, lung, and thymus; myeloproliferative neoplasms; and systemic mastocytosis. 